\title{
Technology, Diversity, Web Accessibility, and ALA Accreditation Standards in MLIS
}

\section{Author}

Adina Mulliken, Hunter College, City University of New York

\begin{abstract}
This paper discusses an interconnection between diversity and technology: web accessibility for all, including people with disabilities. Qualitative interviews were conducted with eight MLIS professors and two students or recent alumni. The findings showed that attitudes regarding teaching web accessibility and recruitment of a diverse student body varied between professors who were familiar with web accessibility and those who were not. Participants familiar with web accessibility often thought it should be included within ALA Standards for Accreditation. The findings suggested that, in one school, incorporating diversity in their curriculum, including web accessibility, allowed recruitment of a more diverse student body and was furthering diversity-related curriculum content. At another school, a professor expressed concern about recruiting a diverse student body, particularly students with disabilities. The research suggests that stronger practices for teaching technology, teaching diversity, and recruiting diverse students could assist the field of LIS to further realize its inclusive goals.
\end{abstract}

Keywords: diversity, web accessibility, disabilities, LIS curricula, accreditation standards

Q uestions have been brought up in the literature and among faculty about whether Masters of Library and Information Science (MLIS) schools should teach specific technology skills to future librarians. Some Library and Information Science (LIS) faculty and students also question whether LIS schools or curricula adequately address diversity. This paper discusses an interconnection between diversity and technology, namely, web and digital accessibility for all, including people with disabilities. ${ }^{1}$ The findings of this qualitative research study of LIS faculty and students or recent alumni support the idea that stronger practices for teaching technology, for teaching diversity, and for recruiting diverse students could assist the field of LIS in moving toward realizing its stated principles of equal inclusion. ${ }^{2}$ In addition to these issues, the paper discusses questions about whether ALA Standards for Accreditation could foster such teaching or educational practices in MLIS. The study primarily focuses on MLIS programs, but discusses literature, standards, and professors' comments about LIS in general when relevant.

\footnotetext{
${ }^{1}$ Although similar issues are likely to be relevant for digital accessibility in general, the study primarily focused on web accessibility because websites are widely created, selected, and used in libraries.

2 American Library Association's "Library Bill of Rights" says library resources should be provided for "all people of the community the library serves" (American Library Association, 1996). ALA further interprets the Bill of Rights in its "Services to Persons with Disabilities: An Interpretation of the Library Bill of Rights," which states, "All library resources should be available in formats accessible by persons of all ages with different abilities" (American Library Association, 2009c).
}

International Journal on Information, Diversity and Inclusion, Vol. 1, 2016 nublich lih umd edı/IIITI/ 
Open-ended interviews were conducted with eight MLIS professors and two graduate students or recent alumni. The findings showed that participants who were familiar with web accessibility felt more strongly about possible ways to include it in the curriculum, while participants who were less familiar suggested that a more general treatment of diversity was appropriate. Some participants seemed to suggest coding skills need to be taught in order for students to understand web accessibility. Additionally, there were varied attitudes between professors who were familiar with web accessibility and one who was not in regards to recruitment of a diverse student body. The results also showed that participants who were familiar with web accessibility often thought it should be included within the Standards for Accreditation, while two of the participants who were not teaching web accessibility questioned whether this would be too prescriptive. The findings suggested that, in one school, incorporating diversity in their curriculum, including web accessibility, allowed recruitment of a more diverse student body and was leading to the addition of further diversity-related content, including web accessibility, in the curriculum. Professors at this school suggested there were advantages to considering broader diversity issues, such as race and ethnicity, together with disability. Meanwhile, at another school, a professor expressed concern that setting a goal to recruit a diverse student body, particularly students with disabilities, in LIS would be too difficult.

This paper does not directly investigate the advantages and disadvantages regarding specificity versus generality of the ALA Standards for Accreditation. While issues of specificity versus generality were often brought up during interviews for this study in relation to whether the Standards for Accreditation should, or could, include stronger support for diversity and web accessibility, the general question of specificity versus generality involves issues beyond the scope of this paper.

An introduction to digital accessibility ethics, policy, or technology is not included in this paper. An introductory summary of the ethical reasons and legal requirements to make publicly available digital resources - such as library websites and library e-resources - accessible to all, including people with disabilities, at the same time they are made available to people without disabilities, is available in Mulliken and Djenno (2017). Further introductions are available from the website WebAIM: Web Accessibility in Mind (2014).

\section{Literature Review}

\section{LIS Standards Implying Librarians Need to Understand Web Accessibility}

A variety of standards from professional organizations strongly imply or directly state that librarians should have an understanding of digital accessibility, as well as related topics such as assistive technology. The American Library Association's "Library Services for People with Disabilities Policy," which was approved in 2001, says:

All graduate programs in library and information studies should require students to learn about accessibility issues, assistive technology, the needs of people with disabilities both as users and employees, and laws applicable to the rights of people with disabilities as they impact library services (American Library Association. ASCLA, 2001).

Additionally, the Association of Specialized and Cooperative Library Agencies (ASCLA) division of ALA created a guide to buying accessible digital materials. Its introduction explains, "Libraries

International Journal on Information, Diversity and Inclusion, Vol. 1, 2016 publish.lib.umd.edu/IJIDI/ 
share a great responsibility ... to ensure that anyone - especially patrons and staff with disabilities - can effectively use ... electronic services" (American Library Association. ASCLA Ad Hoc, n.d.). In 2009, ALA adopted the "Resolution for Purchasing of Accessible Electronic Resources," which says, "The American Library Association (ALA) Council [the governing body of ALA] is recommending that all libraries purchasing, procuring, and contracting for electronic resources and services require vendors to guarantee that they comply with widely accepted accessibility standards" (2009b).

In addition to ALA, the 2012 "Report of the ARL [Association of Research Libraries] Joint Task Force on Services to Patrons with Print Disabilities" recommended that "accessibility service awareness needs to be a standard part of staff training" (p. 9). It then states, "Research libraries have a responsibility to make library collections and services universally accessible to their patrons. Doing so is consonant with research library community values and is also necessary in order to comply with long-standing legal requirements" (p. 4).

Finally, the Association of College \& Research Libraries (ACRL), which is a large division of ALA, has a set of standards passed in 2012 titled "Diversity Standards: Cultural Competency for Academic Libraries." They call for "collection managers [to] be attentive to represent[ing] the linguistic needs of library constituents, and [to] assure that library resources in print or electronic formats are available, especially to support the academic curricula reflecting all diversity issues, including those of visually disabled constituents" (ACRL, 2012).

These standards and statements from three of the most prominent librarian professional organizations in the United States strongly imply or directly state that competent librarians should, at the very least, be taught to have a basic understanding of digital accessibility. This is implied because such an understanding would be necessary in order to enact the recommendations to ensure that patrons with disabilities can use electronic resources and to make collections universally accessible.

\section{Diversity, Including People with Disabilities, in LIS Curricula}

It is reasonable to believe that the presence of disabled faculty and students, who are most directly affected by accessibility issues, may lead to greater awareness of digital accessibility among the rest of the faculty and students. For example, if a blind student is in a class, the professor and others are likely to find out if the online course materials are accessible to the student's screen reader. Therefore, the issue of including people with disabilities within LIS programs is relevant to the awareness of accessibility, including digital accessibility.

Jaeger, Subramaniam, Jones, and Bertot (2011) state, "Most LIS programs include just enough diversity to ensure that the diversity requirement of the ALA accreditation process is satisfied" (p. 172). They contend, "Recruiting [students] is tied to representation among... LIS faculty, and the presence of diversity in the curriculum is related to the diversity of the faculty" (p. 174). Lack of recruitment of people with disabilities within LIS programs, including faculty and students, therefore is intertwined with a lack of diversity, including accessibility, within the curriculum.

ACRL's "Diversity Standards: Cultural Competency for Academic Libraries" echoes this point about recruitment of people with disabilities affecting the level of knowledge and understanding within the field when they state,

International Journal on Information, Diversity and Inclusion, Vol. 1, 2016 publish.lib.umd.edu/IJIDI/ 
Diversity is one of ALA's five key action areas to ensure high-quality library services to all constituents. Within that mission is the need to recruit underrepresented groups and individuals with disabilities to the profession. It is this diversity that contributes a deeper level of understanding and competence to our daily work. The American Library Association envisions a richly, diverse workforce providing a high level of service to the membership in an environment where respect, appreciation, equity and inclusion are core values (2012).

Bonnici, Maatta, Wells, Brodsky, and Meadows (2012) did a three-part study by contacting LIS administrators, examining course descriptions, then following up on some course descriptions by contacting professors for further clarification. These researchers found that of 99 courses, 25 covered "physiological challenges," which they define as "visual impairments and physical challenges" (p. 115), and 19 covered "socially classified diversity," which Bonnici et al. define as "race, ethnicity, gender and sexual orientation" (p. 118). They state,

It is evident that diversity is defined by the LIS curricula as constituting service to patrons with physiological [diversity] as well as patrons classified as socially diverse. However, more often than not, the curricula reflect that these diversity topics are dealt with as mutually exclusive topics with each having a course dedicated to their specific issues (p. 125).

Bonnici et al. argue for a more "comprehensive philosophy of access where goods and services are distributed across a more broadly defined population of both socially and physiologically identified user groups. Such a foundation would consistently withstand societal changes and the evolution of groups considered as diverse" (p. 125).

There is agreement between Jaeger et al. (2011), ACRL's "Diversity Standards: Cultural Competency for Academic Libraries," and Bonnici et al. (2012) in that there are advantages in paying attention to relationships between various minority and disadvantaged groups, including people with disabilities, while teaching or improving the state of knowledge in the field. There is also agreement between Jaeger et al. (2011) and Bonnici et al. (2012) in that including diversity in the LIS curriculum is related to diversity among the body of students and faculty.

\section{Web Accessibility in LIS Curricula}

A number of studies summarized by Mulliken and Djenno (2017) as well as Schmetzke's (2015) study and literature review suggest that web accessibility is not covered adequately in LIS curricula. Additionally, Oxley (2013) reports that, from her perspective as a recent alumna who started an LIS student organization about diversity,

When students and staff are deprived of cultural competency training, not exposed to research that reflects implication on diverse populations, and not exposed to tenets of inclusive and accessible design of information structures and services, they may be unaware of both the existing knowledge gap and the importance of diversity (p. 237).

\footnotetext{
${ }^{3}$ Disability Studies scholars frequently resist a strictly physical, medical, or essentialist conceptualization of disability and offer a social model alternative. Therefore, they might disagree with Bonnici et al.'s definitions. However, in my view, the conclusions Bonnici et al. reach do not conflict with a Disability Studies perspective in spite of differences in definitions.
}

International Journal on Information, Diversity and Inclusion, Vol. 1, 2016 publish.lib.umd.edu/IJIDI/ 
Lack of awareness of the knowledge that is being missed is likely to perpetuate the gaps in the curriculum.

\section{Technology in LIS Curricula}

The issue of the depth in which technology in general is covered in LIS programs may be relevant to the question of how well digital accessibility technology is covered in LIS. Riley-Huff and Rholes (2011) studied how much technology is covered in LIS programs. They studied course descriptions for technology courses and concluded that technology course offerings had been increasing, but not all LIS programs offered essential courses and there was a lack of advanced technology courses. They found a wide variation in the number of technology courses, as well as the content of the courses, from one program to another.

Singh and Mehra (2013) also studied coverage of technology within LIS curricula and also found it lacking. They studied course descriptions and tallied how many schools were offering courses in 25 areas of technology that they had found to be important. Many schools did not cover all the areas. Singh and Mehra did not mention web accessibility, though it might be considered inherent in web design, which they do mention. They found that 18 of the 25 schools covered web design and development, which was more than for many of the other technology topics.

Hall in 2008 studied core curricula in 55 LIS schools. Building on previous studies, he found "information technology had the greatest increase since 2002, jumping more than $50 \%$ " (Hall, 2009 , p. 64). He points out that this is not a surprise because of the increase in computers in libraries during that time. He concluded from his research,

There definitely appears to be a common set of required subject areas. It also seems that LIS programs are modifying their core curricula to meet the changing complexities of the information environment, particularly as evidenced in the increase in programs that require information technology (IT) classes (p. 66).

The trend of these studies, with the exception of Hall's older study, seems to be that technology coverage is not robust in LIS. Hall's finding contrasts somewhat with Riley-Huff and Rholes (2011), perhaps because Hall considers semi-core courses, which are not necessarily required for all students, to be part of the core. Hall's (2008) conclusions differ from Singh and Mehra (2013) because Hall did not look into specific aspects of IT coverage. Technology coverage may relate to coverage, or lack thereof, regarding web accessibility.

\section{Methods}

Qualitative, loosely structured interviews were chosen for the present study in order to allow indepth discussion of issues raised by faculty and student interviewees. Interviewees were encouraged to preview a short list of potential interview questions to give them a general idea of the interview topic and scope. Interviewees were then encouraged to talk freely on issues they believed were relevant, without being limited by the questions.

The methodology of this study is originally described in an early paper that reports additional findings from the same study (Mulliken \& Djenno, 2017). Loosely structured, open-ended interviews in qualitative research allow researchers to explore topics in depth and without predetermined interview questions biasing the results. Bogdan and Biklen (2007) articulate,

International Journal on Information, Diversity and Inclusion, Vol. 1, 2016 publish.lib.umd.edu/IJIDI/ 
When the interviewer controls the content too rigidly, when the subject cannot tell his or her story personally in his or her own words, the interview falls out of the qualitative range. [In unstructured interviews], the researcher...encourages the subject to talk in the area of interest, then pick[s] up on the topics and issues the respondent initiates (p. 104).

Qualitative research does not lead to generalizable results. The study presented here hypothesizes potential implications based on the data available. The results can be used to inform further research or, particularly in the absence of such studies, to suggest considerations for current decisions that have to be made.

The study was approved by internal review boards at Syracuse University and at the University of Illinois in Chicago.

\section{Participants}

As explained in Mulliken and Djenno (2017), library science literature, professional acquaintances, and referral sampling were used to identify potential interviewees. The criterion was that participants had demonstrated interest or involvement in any aspect of accessibility. Involvement included having publications, having taught classes, or having participated in professional activities related to accessibility in libraries. For students or recent alumni, involvement included activities related to accessibility within student organizations or course work. Investigators chose participants in this category with the idea that these participants might have more insight into the issues than faculty who taught relevant subjects like web design but who were not known by the investigators to have awareness of accessibility.

One investigator contacted the prospective interviewees by email. All but one candidate agreed to be interviewed. Eight professors who teach courses in MLIS and two graduate students or recent alumni, all of whom have been involved in accessibility, were interviewed. Not all interviewees had knowledge of web accessibility, specifically.

\section{Data Analysis}

All interviews were transcribed by the investigator. Following common practice in qualitative research, themes or codes were generated from the transcripts instead of using predetermined questions or presumed categories to analyze the results (Bogdan \& Biklen, 2007). Transcripts were read a minimum of three times and recoded several times. Final themes that emerged included views regarding teaching introductory web coding such as HTML and CSS, views about ALA Standards for Accreditation, and views about diversity. Additional themes also emerged and were addressed in an earlier paper, and so are not addressed in this article. The pronouns "he" and "she" have sometimes been changed in this article to protect the identity of participants.

\section{Results and Discussion}

\section{Views Varied Regarding Teaching Introductory Web Coding}

One of the issues that came up in this study was the question of whether basic web coding should be taught, or even required, in core courses within LIS curricula. Faculty who were doing more in-depth teaching of web accessibility favored teaching introductory web coding skills, such as

International Journal on Information, Diversity and Inclusion, Vol. 1, 2016 publish.lib.umd.edu/IJIDI/ 
HTML and CSS. In the two schools where web accessibility was being taught, it was being taught along with some HTML and CSS. One professor said, "I think maybe that a challenge the LIS schools face is that we are not focused on teaching students skills. If it was me, you know, some of my colleagues who are really championing accessibility, we definitely would make it something that is required." Similarly, a professor from a different school agreed with the interviewer's suggestion that his web accessibility course would work well as a core course, meaning that learning some HTML and CSS would be required. There were several reasons for this. He explained that some students in his course had skills that were too advanced for the course, so it was difficult to keep them engaged. Making it a required course for the degree could prevent students from taking it later in their program, after they had taken more advanced courses. This way, students would learn standard, accessible coding from the beginning. He explained that he had to re-teach students. He said,

Well, ... I would not recommend separating accessibility from learning HTML and CSS. Partly because from my perception or my experience, accessibility for the web begins at a code level and if you're doing remediation where you're going back into the code to remediate it's not always successful and it's almost always painful and not cost effective. So, in an ideal world, I like the way that I'm able to teach the class with accessibility baked in from the very beginning. ... I have [had] ... students who are familiar with HTML, but I'm spending a great deal of my time retraining them.

The professor explained specific examples of the retraining he needed to do. One example involved alt text. Alt text is a description of a picture on a web page, added in the code by the web designer (WebAIM, 2014). Screen reader software used by blind people to read the computer screen aloud reads the description so that the blind user knows what the picture is. Adding the alt text is one basic requirement of web accessibility standards. The professor said,

Trying to get them to think in terms of accessible alt text... I [had a student] who used ... alt text [for a completely different purpose than it is intended]. Well, it was ... not accessible at all.

Similarly, the professor was concerned about "building their website with tables" because if a web designer uses tables to lay out the webpage, this can cause the blind person's screen reader software to read the webpage in an illogical order. In addition to the alt text and table examples, the professor mentioned the structure of the page - which involves thinking about how users, including screen reader users, navigate a page, such as navigating by headings — which should be included in the code. He said,

... [I'm] trying to get them to think in a different paradigm in terms of how they build the page and how they structure the page. ... I'm not sure if students coming out of [a course that only briefly touches on HTML and accessibility] are going to have ... an understanding of how to build that [accessibility] in from the beginning. So, ideally if I can start from the beginning with a student who doesn't have a lot of preconceptions, who doesn't try to build their website with tables, things like that, I think we'll get farther.

Not only did he give several reasons to learn accessible coding from the beginning, but his statement that "accessibility for the web begins at the code level" suggests that it may be important to learn some coding in order to understand web accessibility.

International Journal on Information, Diversity and Inclusion, Vol. 1, 2016 publish.lib.umd.edu/IJIDI/ 
Besides needing to understand some code to have a grasp of web accessibility, other professors agreed that integrating coding and web accessibility into the curriculum is important because of the need to include accessibility in planning and creating a website. The concept of accessibility at the outset means that the website or digital resource is made accessible to everyone at the same time, rather than made available to people without disabilities first and then fixed to be accessible to people with disabilities later. Accessibility at the outset may be contrasted with the tendency to rely on segregated special educators, disability services, or disability offices to retrofit or find other workarounds. An example of this is trying to fix problematic web or digital resources after a person with a disability is known to need the resource, meaning that he or she may have already encountered a problem and been delayed.

One professor who was teaching web accessibility in some depth explained some reasons why librarians could use some basic level of knowledge about this topic, demonstrating the frequently raised concern for equal accessibility at the outset and learning it at a deeper than superficial level.

So, but now, I'm teaching a course .... and so in researching that and getting information for my classes to prepare to teach my students, I'm learning a lot about web accessibility. I guess I'm learning that the term accessibility, not everybody sees it the same way? ....

Some people think it's, well, if my site is pretty, it's accessible. And that's not all there is to accessibility. There are things that have to be put in place on the front end so that people with varying abilities will be able to use it.

This professor clearly understood that there are reasons for web accessibility to be taught at the outset, as soon as an LIS student learns about creating a website, although the professor was still learning about how to do so himself. Additionally, he contended that web accessibility, specifically building accessible websites, should be taught in more depth within LIS. He said,

Yeah, well, for one I think that there needs to be an awareness in general. I don't think many people spend any time thinking about it; it's not their research area and if they don't have issues accessing a site, most people if they have any trouble, they just go to another site. But for people with disabilities, that could be the majority of the sites they go to, they're unable to access. ... But answering your question about what faculty should be aware of, they should be aware of, in general, that there are web accessibility standards, and that, [for] example, our professors that teach classes that are... more information management, or more building websites, they need to be infusing that into their curriculum, somehow, because it is a top down thing, you should not be going in afterwards and saying, "oh."

Respondents demonstrated reasons that web accessibility should be taught at least to the level of depth that it was being taught, or in greater depth. For example, a professor explained the level of depth in which one program covered web accessibility:

The course where we introduce them to universal usability and universal design programming aspects of different populations and how they interact with technology ... I devote a few weeks to explain to my students about the need of having web accessibility. And also, being familiar with the guidelines... WCAG, 508, so my students will get used to all that. Across the weeks we talk about different populations so let's say we talk about people who are blind and we [discuss] the issues of access that they have ... so there are

International Journal on Information, Diversity and Inclusion, Vol. 1, 2016 publish.lib.umd.edu/IJIDI/ 
several ways that accessibility in some way is in every week that we talk about human populations.

A recent graduate of this program was asked whether she felt her courses "went a lot into web accessibility topics." She explained,

I know that we had ... several readings on them. We had readings on user experience, we had readings on web accessibility... academic, published publications. We also had some readings for a class that were more on the community journal level that were maybe talking about, let's say, patrons who aren't sighted and dealing with using screen readers. But they're short and essentially for the practitioner to raise awareness .... Mostly we were sort of made aware of it? And there was some project-based learning to kind of try out what it would be like to retrofit certain things... you've probably come across the fact that very little is created with web accessibility in mind, and often times we're retrofitting technologies or retrofitting access...

The student explained that as a result of what she learned, in her professional job "if I'm doing my website I make sure that if I put up a picture, I make sure that I put target data behind it that describes it."

Further, she demonstrated depth in her understanding of web accessibility, even while pointing out that her awareness was at a beginning level. For example, discussing accessibility of subscription resources at her library, she said,

Now [name of a particular database] does have captioned videos. .... Some of the databases have read aloud, but I think it's more to address kids with print disabilities, or struggling readers. If you were a screen reader [user], I have no idea what that would look like. I'm not sure how Jaws, for example, would [work with it]. We don't have any students ... with blindness, deafness, or deafblindness, so I haven't really seen that in action.

She explained she had used a trial of the Jaws screen reader and had seen a demonstration of it during her coursework. Therefore, she was able to understand that, since blind users already need to be using their own screen reader software to get to any of the library's electronic database features, the database's read-aloud function is not an essential feature for them. Rather, the database needs to comply with standards to allow blind users to navigate with their own screen reader. Accessibility novices sometimes think that the read aloud would be useful for blind users. The recent graduate perceived this is not necessarily the case, which suggests that her understanding is more educated.

The same librarian, who was a recent graduate and had been a student in one of the programs where web accessibility was taught in more depth, suggested that there were some reasons she felt that more focus on accessibility would be ideal. This librarian said numerous times that she felt lucky to have stumbled onto professors who covered this topic. Still, she said,

If we ... as a nation or as a culture of American libraries [were more concerned]... then you could have highly specialized courses that you wouldn't have to seek out, 'cause I feel like information management, other courses, all these great user experience courses, highly specialized courses where they're going into labs and they're really doing ... you know, they have a little more autonomy, maybe a stronger sense of potency that "I myself

International Journal on Information, Diversity and Inclusion, Vol. 1, 2016 publish.lib.umd.edu/IJIDI/ 
can do this" [in comparison to librarians' confidence with web accessibility], and it's just as natural as, you know, sticking on the bar code label and sticking it on the shelf.

Although her school seemed to have more in-depth coursework on accessibility than other schools, she still sensed that it was not as much as needed. She continued,

But for that to happen, there'd have to be a shift first of all in attitude, major shift in leadership, not only within LIS education but within ... leadership, I'm just going to come right out and say: ALA, and, you know, then, that would alter the expectations of students who are coming in. ... I guess, also management on the practitioner level.... What skills are they saying I demand from... outgoing graduate ... or academic libraries, you know, when people are being hired ... being asked, you know, these are deal-breaker skills, you have to have these skills. And I think that right now, that's not happening. To my knowledge, unless you get lucky and get a professor who thinks that's very important, I do not think that [web accessibility] is a major or even a small part of a typical part of a typical American MLS training.

In summary, professors who were teaching web accessibility, or learning to teach it, often contended that it should be taught at a level of depth that included basic coding and that basic coding should be taught. The student who had been in a program that taught this suggested that even more depth would be needed to allow librarians to operationalize web accessibility and that this would need support above the level of individual LIS schools.

One professor who was not teaching web accessibility had a different perspective than faculty who were doing so. This professor suggested that maybe web accessibility should be taught as a separate workshop, not as part of the curricula. As reported in Mulliken and Djenno (2017), the professor suggested it might not be graduate-level content. The professor said,

I think it [web accessibility] should be taught. I think the question is going to be where. In what classes would it be taught, and, again, is it something that would be appropriate for graduate education. I sound like [I'm being tough.] I'm not trying to be, but I know there are some things when we talk about we should teach blah, blah, blah and you think well, really, is that a graduate class? Or are we talking about things that really should be taught in undergraduate level?

The view that web accessibility and the related coding might not be appropriate for a graduatelevel class contrasts markedly with the views of faculty who were doing more in-depth teaching of web accessibility, HTML, and CSS.

\section{Views Varied Regarding ALA Standards for Accreditation}

Faculty who related that they had knowledge of web accessibility tended to respond positively to the idea that something related to web accessibility should be included in ALA accreditation standards. These faculty also acknowledged they did not know a lot about ALA Standards for Accreditation, but believed that a policy that specifically addressed web accessibility would help move things in a positive direction. For example, one professor who taught web accessibility said,

I'm not that familiar with it [ALA Standards for Accreditation] but I'm all for it. Anytime they can raise awareness and increase sensitivity, that would be great. Now, I'm not familiar enough with the guidelines to say okay, it needs to go here and here and here. One of the things I think we see here on campus is that when administration buys into the

International Journal on Information, Diversity and Inclusion, Vol. 1, 2016 publish.lib.umd.edu/IJIDI/ 
concept of accessibility and they make that, if not a priority, at least something to be aware of, then that increases awareness all down the line. It's much more difficult for things to bubble up from the grass roots, although they do. It's always nice when you can build something like accessibility into your policy statements and your standards and just increase awareness from that perspective as well.

Another professor who taught web accessibility, when asked if she thought there was a role for the ALA Standards to include more about web accessibility, responded,

I think that would be terrific. But, you know, the ALA has certain assertions of diversity. It would be nice to see those as a package much more specific. And disability included in that as a very clear "this is important to us and this is important to what we hope you will teach." Down to a level of not just "yay diversity," but down to a level of here's the things, you know. And you certainly would hope that ... you know, ideally, and I realize this is very much ideally, but it would be great to have standards that, okay you need to teach people this, this, and this. ... That would be wonderful.

A third professor who taught web accessibility had an immediate response to the question about including web accessibility in accreditation standards: "that would be awesome, wouldn't it?" She went on to explain that the current Standards talk about diversity, but it would be better to have a mandate to cover web accessibility and to have programs cover web accessibility more widely. A professor who was learning about web accessibility responded to the question by saying,

I think it's very important. .... Accessibility at large... needs to be further addressed, not the passing topic that is just touched upon, so to speak. I'm seeing great strides. I've been part of the school for the last [several] years. .... It was always, but I'm seeing a real continued growth and push toward accessibility...

The professors who were not teaching web accessibility tended to respond less enthusiastically to the idea that web accessibility, specifically, should be included in accreditation criteria in some way. They tended to suggest that including web accessibility would be overly prescriptive. In response to a question about including web accessibility, one professor who was not teaching this topic responded,

I'd have to look at the new draft Standards... for ALA accreditation. ... They never have been... and even the new Standards that I've seen aren't that prescriptive... They just basically say, are you dealing with diversity, you know, a wide spectrum of your population, you know, so they have to give some evidence that you're doing that, but it's more of a holistic thing, and they don't go into like, aha, you know, you didn't talk about boys who have Asperger's, so you can't get accreditation.

The professor seemed to be comparing a topic about a specific population with the topic of web accessibility for all, which seems to imply that web accessibility is only one of many aspects of diversity, with no more weight than many other aspects, not all of which can be covered.

Another professor who was not teaching web accessibility had an immediate response that was negative: "No, please no. [laugh]." Like the previous professor, she did not overtly question the

International Journal on Information, Diversity and Inclusion, Vol. 1, 2016 publish.lib.umd.edu/IJIDI/ 
Standards, just restated them. She did, however, discuss in detail how issues of accessibility might fit within the current Standards. ${ }^{4}$ The professor said,

In terms of curriculum, ALA doesn't mandate the curriculum. ... They look for the schools to set their goals and outcomes and then to have the curriculum that supports those goals and outcomes. And so the question would be, does the curriculum have an outcome or goal that's around teaching accessibility? .... But, ALA I don't think would mandate that curricular element.

Needs of a diverse society, including the needs of underserved groups, is part of the curriculum standard. So I think the question would be how people interpret that particular sentence... is that something that might relate to our policy classes? Is it talking about policy around serving people? Is it ethics related? Is it thinking about services to inner city youth? So there's a lot of ways that could ripple through a program without touching people with visual impairments.... So there's lots of ways that particular line or standard could ripple through a program without including materials in a program around dealing with people with visual disabilities...it's, the phrasing is underserved groups...

Here, she pointed out that under the Standards, it is easy for web accessibility and people with visual impairments to be ignored. Although she did not suggest that she believed the Standards should be changed, she did seem to be attempting to find a way to interpret the Standards to include accessibility and acknowledging that it is possible for the topic to be disregarded under the Standards.

\section{Diversity in the Curriculum}

The topic of general diversity, including people with disabilities, came up several times during the interviews. There was concern about whether LIS courses adequately cover diversity. One professor said,

We [the field of LIS] don't always do well with a lot of diversity issues. Some people do well with them, others, it's more of a struggle, you know. So it's - disability isn't unique in that we haven't done well with all other [diversity issues] and I think that's kind of contextually a significant thing because it's very much part of a package.

Although diversity in LIS overall was a concern, the school at which that professor worked did teach diversity, including web accessibility.

The topic of general diversity came up again when another professor at the same school, who teaches web accessibility as a part of diversity, explained that she discusses poor, homeless, and

\footnotetext{
${ }^{4}$ At the time of the interview, the previous version of the Standards for Accreditation were effective, although the current standards are similar in that they do not specifically address web accessibility. The 2015 Standards only mention accessibility for people with disabilities (not web accessibility specifically) under the category for "Administration, Finances and Resources," not under "Curriculum" (Council, 2015, p. 9). Also similar to the earlier 2008 Standards, the 2015 Standards Curriculum section says, "Student learning outcomes address...the role of library and information services in a diverse global society, including the role of serving the needs of underserved groups" (Council, 2008, and Council, 2015, p. 4). Unlike the 2008 Standards, the 2015 Standards state, "the curriculum provides...for the study of...legal and ethical issues and values necessary for the provision of service in libraries and information agencies..." This could be construed to cover web accessibility, although, similar to the previous Standards, web accessibility could be disregarded in the way the professor described.

International Journal on Information, Diversity and Inclusion, Vol. 1, 2016 publish.lib.umd.edu/IJIDI/
} 
socioeconomically challenged people who may rely on cell or smartphones for web use since they are much cheaper than broadband. She pointed out the overlap between accessibility for this group and for people with disabilities in this example. A person using adaptive technology may be disadvantaged by webpages that load slowly, just as people who have slower connections for economic reasons are disadvantaged. She also pointed out that the capacity of some devices to translate for users who do not speak English fills a similar need as captioning for users with hearing-related disabilities. Yet another intersection that she mentioned between people with disabilities and other groups was older adults acquiring disabilities they did not have growing up and needing various aspects of websites to be accessible, the same as people who have disabilities earlier in life.

Diversity in the curriculum therefore was approached as discussing these various diverse groups together. This fits Bonnici et al.'s (2012) argument that a more "comprehensive philosophy of access where goods and services are distributed across a more broadly defined population of both socially and physiologically identified user groups," in this case, meaning access to websites for various groups, can more easily "withstand societal changes and the evolution of groups considered as diverse" (p. 125). In other words, if the definition of "access" is considered to be comprehensive, it will not have to be revised each time society evolves and begins to include a new group, such as people with disabilities.

\section{Diversity in Recruitment}

A professor who was teaching web accessibility as a part of diversity at the same school as the professor quoted above said,

In terms of who's drawn to the college, having [the diversity program] is a very clear message to people from groups who aren't as well represented in our field that even if that's not what they want to specialize in, this is a place that will be welcoming to who they are. So we have fairly dramatically higher levels, or representation, of people from a lot of groups who are badly underrepresented in our field, including people with disabilities, because they see, in offering this curriculum - they see a commitment that wouldn't otherwise be conveyed.

Incorporating broad diversity in the curriculum, then, seemed to have positively affected the ability to recruit a diverse student body, including people with disabilities. The more comprehensive concept of diversity may have not only allowed for a more consistent concept of "access" over time, but also allowed the school to act on that broader philosophy of access in its admissions to its LIS program.

This broader philosophy of access, which by its definition included people with disabilities and web accessibility, may also have been leading toward even greater inclusion of web accessibility throughout the curriculum. For example, the support for learning about web accessibility in some depth within the diversity program may have been allowing students and faculty to more clearly understand reasons to move toward including web accessibility in mainstream core courses. Students who had learned about web accessibility in some depth in their diversity courses had begun to open up conversation with professors in other technology courses.

Although this program was successfully recruiting students with disabilities, which seemed to be leading to greater inclusion of web accessibility within the curriculum, a professor at a different school shared concerns that it would be a problem to set a goal of recruiting students with

International Journal on Information, Diversity and Inclusion, Vol. 1, 2016 publish.lib.umd.edu/IJIDI/ 
disabilities. She pointed out that the Standards do not support recruitment of people with disabilities, saying "I don't think there's anything around students or what they look for in your student body that has anything specifically to do with students with disabilities. ${ }^{5}$ " This professor did not suggest the Standards should be changed to support recruiting students with disabilities. She also said,

Actually, there's nothing in the Standards that talk about student diversity. But it is something they look at and something they comment on. So we have to report diversity of our student population - that does not include disability.

The sections about students in both the 2008 and 2015 Standards do, in fact, state "The program has policies to recruit and retain students who reflect the diversity of North America's communities." Although the professor missed this, she knew that diversity is considered. She elaborated her concerns further in the following dialogue.

Interviewer: I was wondering if you think it would be, you know, ideal if more groups were included in whatever is tracked for diversity, even though it might be really complicated to get that to happen...

Professor: The problem is then it becomes a goal. So, for example, if you look at recruiting students of color, where should I go to recruit students of color? Well the Joint Conference of Librarians of Color, I think, it's JCLC - isn't held every year - and that's kind of preaching to the choir. We could recruit at historically black colleges and universities, which we've done, you know, do other things to try to recruit that group, but it's not easy. You know that many people who come to the library profession come in different ways. They kind of recruit themselves. They know that this is what they want. So how do you find those people of color who know that this is what they want? And how much financial effort can you put into recruiting people of color? So if you extended that and said okay we want people who are visually disabled and hearing disabled and we want librarians who can relate to all these different areas, then that becomes something that's tracked, and people say well you should be doing better, but how do you do better? How do you go out and attract someone who is hearing disabled to become a librarian? The person would have had to have gone through a bachelor's program, would have to meet the admission criteria for the graduate program, and would have to have that passion for libraries. And so it becomes, so it's one of those things where I could argue, yeah, we should be tracking these people and wouldn't it be great if ALA tracked that, but then on the opposite side, I know what would happen, because it was trackable then it would become a goal...

Unlike a professor who was recruiting students with disabilities, this professor seemed to understand the possibility of recruiting students of minority groups, including students with disabilities, as a potential problem. She went on,

ALA would not pull someone's accreditation because of diversity. I'm pretty sure of that. Diversity is something they really want us to all strive for; they always comment on [that] when they look at our statistics; but, I think they also realize that diversity is hard.... Yeah, it's tough. It would be wonderful to have a more diverse population, people with

\footnotetext{
${ }^{5}$ The 2008 Standards were in effect at the time of the interview. The 2015 Standards similarly do not reference students with disabilities.

International Journal on Information, Diversity and Inclusion, Vol. 1, 2016 publish.lib.umd.edu/IJIDI/
} 
disabilities, people with different cultural backgrounds. But finding those people who are interested in library science; but there probably aren't enough of them out there- I'm thinking of disability - for every program.

Again, her emphasis on the difficulty of recruiting students with disabilities contrasted acutely with comments of the professor who was teaching web accessibility and who was also successfully recruiting students with disabilities.

\section{Implications}

The sharp contrast between the views of one professor that web accessibility might not be appropriate for a graduate-level class versus the views of faculty who were doing more in-depth teaching of web accessibility, HTML, and CSS probably reflects the deeper knowledge of the faculty who are teaching web accessibility. The faculty teaching web accessibility are more likely to understand the conceptual complexity involved with web accessibility, for example, the need to understand how screen reader users navigate in order to think about a logical and equally user-friendly navigational path through the website for them. The faculty who are teaching web accessibility are more likely to understand the reasons that it is necessary for all librarians to be aware of web accessibility. These reasons include the need to make content accessible at the same time as it is posted online (rather than retrofitting the content later), the essential necessity that web content providers - who are often librarians - be involved in making content accessible, and the need to evaluate all digital resources the library purchases or subscribes to for accessibility, which could be expected to be accomplished by librarians. This understanding of web accessibility and its complexity and relationship to many librarian functions may lead the faculty who are teaching web accessibility and the recent graduate of the diversity program to their beliefs that web accessibility should be covered in more depth within LIS, rather than that it should only be taught at an undergraduate level.

Furthermore, the belief among faculty teaching web accessibility that coding should be taught seems to reflect their knowledge, gained by experience, that web accessibility is best taught in conjunction with basic coding. This may be because understanding at least a little bit of coding is fairly integral to understanding web accessibility.

The professors' idea that basic coding should be taught in LIS coheres with the literature reviewed in this article, which argues that more technology should be covered in LIS. The professors' beliefs that coding should be taught, as well as the literature arguing more technology should be taught, may suggest that, in some situations, at least a minimal increase in technical knowledge is necessary in order to adequately inform the conceptual knowledge and values taught in LIS. Specifically, this is relevant to the concept of usability and to the value of inclusion, as well as other concepts and values.

The effort at one school to include web accessibility as part of diversity in the curriculum, according to the professor's report, had positively affected the ability to recruit a diverse student body, including people with disabilities. The professors at the school where this was happening articulated ideas of broad diversity, reflective of Bonnici's broader philosophy of access, which combines disability and other aspects of diversity in the same course. This contrasts with the professor who was concerned that setting goals for recruitment of diverse students, particularly students with disabilities, would be problematic. The contrast might be because the latter professor had less experience with a curriculum that was as broadly inclusive and less experience

International Journal on Information, Diversity and Inclusion, Vol. 1, 2016 publish.lib.umd.edu/IJIDI/ 
with successfully recruiting a more diverse student group. Perhaps such experience would lead to confidence that a broader coalition of diversity could make recruiting diverse students less difficult.

Further studies of the qualitatively informed hypotheses reported here could further clarify the issues. For example, quantitative or mixed method studies could examine the extent to which additional LIS schools have experienced success in fostering a diverse curriculum, inclusive of web accessibility, or in recruiting a diverse student body, including students with disabilities. Additional qualitative studies could further investigate potential reasons for success and barriers to it.

The professors who did not teach web accessibility pointed out that ALA Standards for Accreditation, particularly those for curricula, tend to be broad and not prescriptive. A review of the Standards shows this to be accurate. One part of the standards for curricula in force at the time of the interview says, "The design of specialized learning experiences takes into account the statements of knowledge and competencies developed by relevant professional organizations ${ }^{6}$ " (Council of the American Library Association [Council], 2008). ALA lists such statements on their webpage, titled "Knowledge and Competencies Statements Developed by Relevant Professional Organizations." They include "Core Competencies of Librarianship" (American Library Association, n.d.-b). So, the Core Competencies of Librarianship are indirectly tied to the ALA standards for curricula.

The Core Competencies document states, "This document defines the basic knowledge to be possessed by all persons graduating from an ALA-accredited master's program in library and information studies." (American Library Association, 2009a, p. 1) The Core Competencies Document lists ethical as well as legal knowledge as a competency. It says,

A person graduating from an ALA-accredited master's program in library and information studies should know and, where appropriate, be able to employ:... 1A. The ethics, values, and foundational principles of the library and information profession.... [and] $1 \mathrm{G}$. The legal framework within which libraries and information agencies operate. That framework includes laws relating to copyright, privacy, freedom of expression, equal rights (e.g., the Americans with Disabilities Act), and intellectual property. (American Library Association, 2009a, pp. 1-2.)

Additionally, the document has a section on Technological Knowledge and Skills, which lists, "4B. The application of information, communication, assistive, and related technology and tools consistent with professional ethics and prevailing service norms and applications" (p. 3). It seems that, if the Core Competencies were to be changed, it would work well to add digital accessibility along with knowledge of assistive technology. It is a significant omission that digital accessibility is not yet included. It also seems appropriate that rather than only mentioning one law, the Americans with Disabilities Act, the document could mention additional web accessibility related laws, including the Rehabilitation Act, the Individuals with Disabilities Education Act, and the $21^{\text {st }}$ Century Communications and Video Accessibility Act. Furthermore, the general phrase

\footnotetext{
${ }^{6}$ This was slightly reworded in the 2015 Standards, which says, "Design of general and specialized curriculum takes into account the statements of knowledge and competencies developed by relevant professional organizations"

(Council, 2015). The addition of the word "general" in the 2015 Standards seems to more clearly include the "Core Competencies of Librarianship".
}

International Journal on Information, Diversity and Inclusion, Vol. 1, 2016 publish.lib.umd.edu/IJIDI/ 
"accessibility law" could be used to collectively refer to other unconsolidated laws, regulations, complaint resolutions, and case law, which would be too lengthy to specify in the Standards.

According to the resources listed on ALA's "Resources for External Review Panelists" (American Library Association, n.d.-a), which are for panelists who perform accreditation reviews, it is not entirely clear how the Core Competencies may be included during accreditation reviews or whether including digital accessibility in this Core Competencies document would facilitate its actual inclusion within LIS curricula.

None of the professors suggested that the current Standards are addressing web accessibility via the reference in the Core Competencies to the ADA. Most of the professors, with one exception, were not intimately familiar with the Standards, so it is understandable they had not analyzed wording for possible ways that web accessibility might be encompassed within them. However, not even professors who teach web accessibility indicated that anyone, including themselves, is currently interpreting the Standards to be inclusive of web accessibility. It seems unlikely that the brief reference in the Core Competencies to "equal rights (e.g., the Americans with Disabilities Act)" will, by itself, lead to such an interpretation.

The professors who did teach web accessibility primarily expressed concern that web accessibility be taught in LIS curricula. Although they were not clear about the specifics of how this might be brought about through the Standards for Accreditation, they tended to suggest that they thought generalities such as diversity were too broad, and inclusion of web accessibility in the Standards was appropriate.

Both professors who were teaching web accessibility, as well as those who were not, indicated that general references to diversity allowed web accessibility to be glossed over. However, those who do not teach web accessibility did not suggest that this sidelining was necessarily problematic. Possibly due to their lack of knowledge of the subject, they might not have believed that web accessibility needs to be taught to all LIS students or that it is a particularly core diversity topic in LIS.

Given the general nature of the Standards, it is not clear how web accessibility could be included other than indirectly via strengthening the wording of the Core Competencies. This may not be enough to resolve faculty concerns that web accessibility is not being taught as widely as it should be. The Standards overall might have to allow for more specificity in order to address such concerns. If such specificity is not desirable, at the very least, the need to teach LIS students about minimal compliance with web accessibility law warrants consideration in some way within the LIS accreditation process.

This study suggests areas for further action, investigation, or research. This study did not systematically contact faculty at a large sample of LIS programs, nor did it attempt to contact faculty who primarily teach courses such as Information Infrastructures or other courses where web development and technology are likely to be taught. Further studies could yield a broader picture of the state of web accessibility within LIS curricula and a broader picture of faculty views of it.

In conclusion, this qualitative research reveals the views of a small sample of MLIS professors and MLIS graduate students regarding several themes that emerged from the study, including whether to teach coding along with web accessibility; teaching digital accessibility as part of a broader concept of access for all; views about recruiting diverse students, including students with

International Journal on Information, Diversity and Inclusion, Vol. 1, 2016 publish.lib.umd.edu/IJIDI/ 
disabilities; and views about web accessibility in Accreditation Standards. These views, as well as the literature reviewed, can be taken to suggest that stronger practices for teaching technology, for teaching diversity, and for recruiting diverse students could support the field of LIS in moving toward realizing its stated principles of equal inclusion. Perhaps even more importantly, the views reported here can be used as a foundation for further reflection, action, and research.

\section{Acknowledgements}

I would like to thank Mireille Djenno, African Studies Librarian at Indiana University, for collaborating on research as well as giving encouragement for this article; John Siegal, Associate Professor and Student Success Librarian at the University of Arkansas at Little Rock, and Kerry Falloon, Assistant Professor and Acquisitions Librarian at College of Staten Island, CUNY, for providing significant editorial assistance; and Mike Marlin, Director of the California Braille and Talking Book Library, for reading the manuscript and providing encouragement. I would also like to thank the research participants for their willingness and openness, which made this study possible.

\section{References}

Association of College \& Research Libraries. (2012). Diversity standards: Cultural competency for academic libraries. Retrieved from http://www.ala.org/acrl/standards/diversity

American Library Association. (1996). Library bill of rights. Retrieved from http://www.ala.org/advocacy/intfreedom/librarybill

American Library Association. (2009a). ALA's core competences of librarianship. Retrieved from http://www.ala.org/educationcareers/sites/ala.org.educationcareers/files/content/caree rs/corecomp/corecompetences/finalcorecompstat09.pdf

American Library Association. (2009b). Resolution for purchasing of accessible electronic resources. Retrieved from http://www.ala.org/ala/newspresscenter/news/pressreleases2009/august2009/accessibi lity_council.cfm

American Library Association. (2009c). Services to people with disabilities: An interpretation of the library bill of rights. Retrieved from

http://www.ala.org/advocacy/intfreedom/librarybill/interpretations/servicespeopledisa bilities

American Library Association. (n.d.-a). Resources for external review panelists. Retrieved from http://www.ala.org/accreditedprograms/resourcesforerp

American Library Association. (n.d.-b). Knowledge and competencies statements developed by relevant professional organizations. Retrieved from http://www.ala.org/educationcareers/careers/corecomp/corecompspecial/knowledgec ompetencies

American Library Association. ASCLA. (2001). Library services for people with disabilities policy. Retrieved from http://www.ala.org/ascla/asclaissues/libraryservices

American Library Association. ASCLA Ad Hoc Committee on Electronic Accessibility. (n.d.). Think accessible before you buy. Retrieved from http://www.ala.org/ascla/asclaprotools/thinkaccessible/default

International Journal on Information, Diversity and Inclusion, Vol. 1, 2016 publish.lib.umd.edu/IJIDI/ 
Association of Research Libraries. (2012). Report of the ARL Joint Task Force on services to patrons with print disabilities (Nov. 2, 2012). Retrieved from http://www.arl.org/focus-areas/copyrightip/2342-report-of-the-arl-joint-task-force-on-services-to-patrons-with-print-disabilitiesnov-2-2012

Bogdan, R. C., \& Knopp Biklen, S. (2007). Qualitative research for education: An introduction to theories and methods (5th ed.). Boston: Pearson.

Bonnici, L. J., Maatta, S. L., Wells, M. K., Brodsky, J., \& Meadows, C. W., III. (2012). Physiological access as a social justice type in LIS curricula. (Survey). Fournal of Education for Library and Information Science, 53(2), 115.

Council of the American Library Association. (2008). Standards for accreditation of master's programs in library $\&$ information studies. Retrieved from http://www.ala.org/accreditedprograms/sites/ala.org.accreditedprograms/files/content /standards/standards_2008.pdf

Council of the American Library Association. (2015). Standards for accreditation of master's programs in library and information studies. Retrieved from

http://www.ala.org/accreditedprograms/sites/ala.org.accreditedprograms/files/content /standards/Standards_2015_adopted_02-02-15.pdf

Hall, R. A. (2009). Exploring the core: An examination of required courses in ALA-accredited. Education for Information, 27(1), 57-67.

Jaeger, P., Subramaniam, M., Jones, C., \& Bertot, J. C. (2011). Diversity and LIS education: Inclusion and the age of information. (Library and Information Science) (Report). Fournal of Education for Library and Information Science, 52(3), 166.

Mulliken, A. \& Djenno, M. (2017). Faculty visions for teaching web accessibility in LIS curricula: A qualitative study. The Library Quarterly, 87(1), 36-54.

Oxley, R. (2013). iDiversity and LIS education: Student-based groups promoting cultural competence as a vision for the profession. The Library Quarterly, 83(3), 236.

Riley-Huff, D. A., \& Rholes, J. M. (2011). Librarians and technology skill acquisition: Issues and perspectives. Information Technology and Libraries, 30(3), 129-140.

Schmetzke, A. (2015). Collection development, e-resources, and barrier-free access. In B. Wentz, P. T. Jaeger, \& J. C. Bertot (Eds.), Accessibility for persons with disabilities and the inclusive future of libraries (Advances in Librarianship, Vol. 40), (pp. 111-142). Bingley, UK: Emerald Group Publishing Limited.

Singh, V. \& Mehra, B. (2013). Strengths and weaknesses of the information technology curriculum in library and information science graduate programs. Fournal of Librarianship and Information Science, 45(3), 219.

WebAIM: Web Accessibility In Mind. (2014). Introduction to web accessibility, last modified 4/22/2014. Retrieved from http://webaim.org/intro/

International Journal on Information, Diversity and Inclusion, Vol. 1, 2016 publish.lib.umd.edu/IJIDI/ 